\title{
Estimating the impact of obesity
}

Katherine M. Flegal, PhD is distinguished consultant at the National Center for Health Statistics, Centers for Disease Control and Prevention, Hyattsville MD USA and a visiting scientist at the Center for Weight and Health, University of California at Berkeley, California, USA

How to assess the impact of obesity on a population? Neilson and Schneider (2005) calculated the effects of obesity on health in Switzerland, and Schmid et al. (2005) calculated the effects of obesity on Swiss health care costs. Before being blinded by their dazzlingly large numbers, we need to take a look behind the scenes. Both papers combine estimates from different sources - that is, the population prevalence of obesity comes from one source, relative risks from another source, and data on health conditions or health costs from a third source. The idea of combining data from multiple sources to arrive at population estimates is attractive in its apparent simplicity, but it raises a host of issues.

These two papers continue several unfortunate trends in the obesity literature. Both use a simple attributable fraction formula to calculate the proportion of health conditions or of costs that are attributable to obesity. This formula uses only estimates of the population prevalence of obesity and of the relative risk associated with obesity. These papers thereby perpetuate what Rockhill et al. (1998) called the most common error in calculating attributable fractions the error of using adjusted relative risks in a formula that is only appropriate for unadjusted relative risks.

When data on obesity prevalence come from one source and the adjusted relative risks come from a second source, individual-level information is not available to calculate attributable fractions correctly. Because confounding factors such as, for example, age, are associated both with the exposure (obesity) and with the outcome (health status or costs), relative risk estimates are usually adjusted for a number of confounding factors. (For example, in the article by Field et al. (2001), sex-specific relative risks were adjusted for age, smoking, and race.) Several statistical approaches are available to adjust attributable fraction estimates for confounding factors (Rockhill et al. 1998; Benichou 2001) but these methods would require individual-level data on exposure, outcome and confounding factors - data that neither Neilson and Schneider nor Schmid have available. Using the incorrect formula and calculating attributable fractions without adjusting for confounding could give rise to an overestimation of the impact of obesity if, as is often the case, older people have both a lower prevalence of obesity and a higher prevalence of health conditions and health costs.

Both papers also ignore the potential for differences in risk by age, which cannot be accounted for without individuallevel data or age-specific relative risks. The relative risks of obesity among the elderly may well be lower than among young or middle-aged people. Because of the high proportion of health conditions among the elderly and the high health care costs incurred by the elderly, estimates of the attributable fraction are sensitive to relative risks among the elderly. Assuming that age-adjusted relative risks are the same for all ages can lead to additional overestimation if the true relative risks are lower in the elderly.

These two papers also perpetuate the practice of estimating the effects of obesity without providing any standard errors or statistical measures of uncertainty. When estimates from different sources are combined, each source contributes additional variance to the estimates. The resultant degree of uncertainty can be quite large. The attributable fraction is not a linear function of the relative risk. At low relative risks, between 1 and 2, a slight variation in relative risk of as little as 0.2 may double or halve the estimated attributable fraction. When the added uncertainty arising from the other data sources is added in, the resulting estimates may be highly imprecise. Schmid et al. (2005) try to address this issue by conducting sensitivity analyses based on possible 
ranges, but this is not a substitute for actual calculation of the standard error, taking into account all sources of variation in the estimates.

Extrapolating to a whole population by combining data sources and using relative risks estimated in epidemiologic studies is difficult. It is a challenge to define the appropriate relative risks that apply to a population (Flegal et al. 2004b). Epidemiologic studies frequently exclude people with disease at baseline, people who are in hospitals or nursing homes, and current and former smokers, and they often do not include the older elderly. The relative risks from such studies are thus applicable only to a relatively healthier subset of the population and may be biased estimates of the association of obesity with health outcomes in the entire population. Further, when relative risks are adjusted for confounding factors, it is necessary to use appropriate methods to calculate attributable fractions and not rely on a simple, but incorrect, formula (Flegal et al. 2004a). The variance from each source needs to be considered in arriving at confidence intervals for the estimates. All these factors need to be taken into account to arrive at an evaluation of the impact of obesity on a population.

\section{| References}

Benichou J (2001). A review of adjusted estimators of attributable risk. Stat Methods Med Res 10: $195-216$

Field AE, Coakley EH, Must A, et al. (2001) Impact of overweight on the risk of developing common chronic diseases during a 10-year period. Arch Intern Med 161: 1581-6.

Flegal KM, Graubard BI, Williamson DF (2004a). Methods of calculating deaths attributable to obesity. Am J Epidemiol 160: 331-8.
Flegal KM, Williamson DF, Pamuk ER, Rosenberg $H M(2004 b)$. Estimating deaths attributable to obesity in the United States. Am J Public Health 94: 1486-9.

Neilson A, Schneider H (2005). Obesity and its comorbidities: present and future importance on health status in Switzerland. Soz Praventiv Med 50: 78-86.

Rockhill B, Newman B, Weinberg C (1998). Use and misuse of population attributable fractions. Am J Public Health 88: 15-9.
Katherine M. Flegal
Schmid A, Schneider H, Golay A, Keller U (2005). Economic burden of obesity and its comorbidities in Switzerland. Soz Praventiv Med 50: 87-94.

Address for correspondence

Katherine M. Flegal, PhD

National Center for Health Statistics

Centers for Disease Control and Prevention

Hyattsville MD 20782

USA

e-mail: kmf2@cdc.gov 